\title{
Saving Water for the Future Via Increasing Plant Literacy of Pupils
}

\author{
Renata Ryplova ${ }^{1}$, Jan Pokorny ${ }^{2}$
}

\begin{abstract}
:
The struggle for mitigation of global climate changes is aimed mostly on $\mathrm{CO}_{2}$ emissions, while the role of vegetation having strong impact on water retention in the landscape and cooling of environment stays out of the focus. The reason is human illiteracy of plant role in our environment having roots already in school education. The vegetation use the majority of solar energy for the water evaporation from leaves and by this way cools itself as well as environment and increase water retention in the landscape. Insufficient understanding of these processes leads to no proper landscape management resulting in further increase of drought and climate further draft interrupted by torrential rains and climate extremes. To stop over drying and ensure sustainable economy and environment for the future it is necessary to increase general public understanding of the principles of solar energy distribution by vegetation and its role in water cycle in the landscape via improving school education. This contribution inform about the new teaching methodology on this topic developed by co -operation of scientists and educators and implemented into the education at Czech basic schools. The results of the survey aimed on the impact of this teaching methodology on students' knowledge of plant role in environment are included and necessity of implementation of this topic into sustainable education is discussed.
\end{abstract}

Keywords: Water, vegetation, solar energy, environmental education, climate:

\section{Introduction}

In spite of numerous international scientific research studies documenting the decisive impact of proper vegetation cover on a sufficient landscape water supply (Sheil, 2018; Ellison et al., 2017; Schneider \& Sagan, 2005; Makarieva et al., 2009), the significant role of vegetation has remained well out of the spotlight from the general public. Most of the activities aimed at mitigation of climate change and global warming causing an ever increasing continental drought merely concern $\mathrm{CO}_{2}$ emissions (IPCC, 2018) while the physiological role of vegetation in cooling the local climate as well as propelling the water cycle is rarely taken into account. The public is largely failing to notice the positive contribution of vegetation to the environment. This attitude toward plants is called "plant blindness" (Wandersee \& Schussler, 1999) and has appeared in scientific literature for a few decades (Uno, 2009; Ryplova, 2017; Amprazis \& Papadopoulou, 2020). Plant blindness leads to plant illiteracy, i.e., a poor knowledge of plants (Uno, 2009) as well as little appreciation of their physiological processes. Amprazis \& Papadopoulou, (2020) named plant blindness a "stumbling block" to sustainable development. Incorrect landscape management because of the lack of knowledge or 
sheer ignorance about the role of vegetation in the hydrologic cycle and solar energy distribution in the landscape have the dire consequence of the increase of continental drought (Pearce, 2020; Sheil, 2018, 2014; Kravcik et al., 2008; Ripl, 2003). The thermodynamic concept of solar energy transformation processes controlled by plants and intermediated by water is used for evaluation of ecosystem services and as a criterion of sustainability (Sejak et al. 2018).

\section{Theoretical framework}

\subsection{The tight correlation between sufficient water supply and the physiological role of vegetation in the landscape.}

The impact of vegetation on the water supply in the landscape is linked to the role of plants in solar energy distribution. The sun has a surface temperature of about $6000 \mathrm{~K}$ and emits short wave radiation at a maximum wave length of about $500 \mu \mathrm{m}$. On a sunny day, up to $1000 \mathrm{~W} . \mathrm{m}^{-2}$ of solar energy comes to the earth's surface. About $20 \%$ of solar radiation is reflected and a substantial part is used for the evaporation of water by plants well supplied with water. Photosynthesis, i.e., biomass synthesis from carbon dioxide uses a very small amount of solar energy, less than $1 \%$. The exchange of gases takes place via stomata; there is up to several hundred stomata on just $1 \mathrm{~mm}^{2}$ of a leaf. For every one molecule of carbon dioxide taken, one molecule of oxygen is released while several hundred molecules of water evaporate.

Water evaporation from plants is called transpiration. It is a process of water uptake by plant roots (together with nutrients). The transport of water via bundle sheets moves to leaves and the evaporation through stomata and partly through epidermis. Transpiration is sometimes considered as a mistake of nature, a kind of trade off for the uptake of $\mathrm{CO}_{2}$. In other words, in order to grow, a plant has to open stomata to take in $\mathrm{CO}_{2}$ and then, inevitably, water has to escape through the open stomata. The term transpiration or evapotranspiration losses should be explained and understood in a positive way particularly regarding the consequent cooling and air-conditioning effect. The plant stands are able to bond several hundred watts of solar radiation per $1 \mathrm{~m}^{2}$ into latent heat of water. For the evaporation of 1 litre of water, approximately $0.69 \mathrm{kWh}$ of energy is used and about 1200 litres of water vapor is formed which later condensates on cool places and solar energy is released. Indeed, vegetation has a double air-conditioning effect of vegetation because it cools by evaporation and transfers solar energy in the form of latent heat in space (to cool surfaces) and in time (from daytime to night) when fog and dew are formed. Vegetation increases relative humidity above its canopy, thereby reducing both incoming solar radiation and the flux of long wave radiation into the cool sky (Pokorny et al., 2010).

Vegetation well supplied with water dampens temperature extremes and supports the short water cycle. The short water cycle may be understood as "water recycling", i.e. water evaporated comes back in form of fog, dew and shower. When water vaporizes from vegetation, the moist heavy air ascends into the atmosphere, condensates in cool places and the water eventually returns back into the landscape in the form of fog, dew and shower. However, when vegetation is removed and the landscape drained, then on sunny days the surface temperature of dry surface reaches $50{ }^{\circ} \mathrm{C}$ or more, the air gets warmer and ascends fast, thereby taking humidity up from the surroundings. The warm 
air of low relative humidity forms clouds high in the atmosphere so water does not come back in the form of an afternoon shower. Warm air blocks the income of wet air from the ocean so the landscape dries. This aforementioned role of vegetation is highly complex. Nevertheless, principles can be shown by measuring incoming solar radiation, surface temperature and relative air humidity with respect to the latent heat of water (Pokorny, 2019; Makarieva \& Gorshkov 2007).

\subsection{The necessity of education to avoid plant illiteracy.}

Water recycling via vegetation in the landscape is crucial for precipitation and accordingly a sufficient water supply (Sheil, 2018; Boyce and Lee, 2017). Dai and Trentberth (2002) confirm that approximately two-thirds of precipitation on land is caused by terrestrial vapour. Hence, proper landscape management which takes into account the role of vegetation for retaining water in the landscape is essential. A general understanding of these processes among the broad population may be achieved by imparting the several goals of sustainable development. First of all, vegetation is necessary to ensure water availability for everyone (goal No. 6. of the UN, 2015). Sustainable cities (goal No. 13) need cooling by means of vegetation. A sufficient water supply in the landscape is certainly required for economic growth (goal No. 8). To be sure, cooling via vegetation takes a part in mitigating climate change (goal No. 13). To avoid inappropriate landscape encroachment causing further water loss, the essential needs for people require that future young landscape architects, farmers, forest managers as well as other authorities like economists or municipal employees to be literate in the basic physiological role of vegetation in the landscape.

To educate the general public in this field, this topic should be included in the science curriculum. Unfortunately, very little attention is paid to this topic in the curriculum at all school levels. In spite of its magnitude, the facts about the role of the cooling role of vegetation in the landscape has not been conveyed in international scientific literature for use in environmental or science education. Likewise, there is no published literature about any research conducted to obtain information regarding the level of knowledge among pupils or teachers regarding this important role of vegetation on the environment.

According to our previous studies conducted in the Czech Republic among novice preservice biology teachers (Ryplova and Pokorny, 2019) or basic school pupils (Ryplova and Pokorny, 2020), the level of pupils' understanding is very low. For this reason, we have developed and implemented into the curriculum the new teaching methodology about the role of plants in solar energy distribution and the water cycle in the landscape. The aim of this contribution is to present this methodology and circulate the results of our didactic survey in order to find an answer to the following research question: Could the new teaching methodology improve the basic school pupils' knowledge of the physiological role of vegetation in solar energy distribution and water cycle in the landscape? 


\section{Methodology}

\subsection{Designing the teaching activity}

New teaching methodology was developed and its impact on the improvement of pupils' knowledge was tested through a project supported by Technology Agency of the Czech Republic (TACR). Researchers from two institutions joined and used their know-how for the development of teaching methodology in three versions to be used in education at three different levels: a) basic school pupils, b) university students (preservice biology teachers) and in-service biology teachers, c) municipal employees (under the auspices of lifelong learning). The new methodology is available online (Pokorny, Ryplova et al., 2020). Scholars from the scientific institution ENKI, o.p.s., long experienced in the field of landscape ecology and hence guaranteeing proper scientific content and adequate instrumentation for pupils' field measurement, co-operate with scientists and educators from College of Education at the University of South Bohemia, guaranteeing a suitable and professional pedagogical methodology.

The developed materials for pupils were put in practise after consulting with basic school teachers. The whole process is conducted over three years in three phases. In 2018 the pupils' pre-instructional conceptions and teachers' opinions were studied and pupils and teachers piloted the outdoor learning activities by using modern measuring devices. Based on the assessment of the results obtained, the learning activity about the air conditioning role of vegetation was developed and tested at schools during the second phase in 2019. According to the results from this phase, the learning unit is to be finalized in the third phase in 2020. This contribution presents the experiences from the first implementation in the second phase, i.e., before the entire finalization.

The teaching methodology regarding the role of vegetation in solar energy distribution and water cycle in the landscape has been designed according to the most recent developments in science education. The interdisciplinary character connects pupils' knowledge of the field of physics (thermal energy, solar radiation, vaporization and condensation), biology (plant water metabolism, water vapor from the leaves), geography (solar radiation and solar energy distribution in the landscape, global hydrologic cycle) and finally chemistry (water vapor, pressure, condensation). Educators currently highlight an interdisciplinary approach in science teaching as one of the fundaments of conceptual change in recent science education development. The reason is the complexity of the systems of nature and related scientific problems, the understanding of which requires a fundamental transdisciplinary background (You, 2017, Golding, 2009). The transdisciplinary way is nowadays regarded as an obligation for sustainable science teaching (Orozco-Messana et al,, 2020). In our teaching methodology, the transdisciplinary way is joined with an inquiry approach as well as place-based learning. Inquiry education is an up-to-date, pupil-centred teaching strategy, believed to enhance pupils' direct engagement in education. During the inquiry activities, the pupils actually obtain knowledge in the similar manner that scientists conduct their research. The teacher acts as a guide, supervising the pupils' activities (Osborne \& Dillon, 2008; Rocard et al., 2007). The inquiry approach may be accomplished to great advantage when combined with place-based education (Smith, 2007).

As stated above, the measurement of solar energy distribution and evapotranspiration at a scientific level is quite sophisticated, requiring highly accurate measurements using 
expensive measuring devises. However, for the documentation of the basic processes in the landscape, these methods may be simplified for the basic school level. Due to the rapid development of technology, modern and inexpensive equipment is already available, allowing pupils to perform the necessary measuring by themselves. Our new teaching methodology recommends for the school measurement activities reliable, user friendly and pocket-sized measuring devices such as solar radiation meters, infrared thermometers and small thermocameras.

\subsection{Design of the teaching activity for basic school}

The teaching activity was constructed according to the 5 E- model of inquiry (Carin, Bass, \& Contant, 2005). The 5 E specifically means: Engagement, Exploration, Explanation, Elaboration and Evaluation as described for our purposes below.

1. Engagement: This step is focused on pupils' motivation. The pupils are asked to imagine a hot sunny day in the city and the cool shade of a tree. The motivation is accompanied by thermovision picture (Fig.1). Pupils are tasked with solving this problem: "Why is the shade under the tree cooler than the shadow under umbrella?" The pupils' engagement for education is connected with their everyday experiences. During a hot summer day, everybody is looking for the cool shade of a tree. Nevertheless, what is the reason for the lower temperature under the tree? Brainstorming.
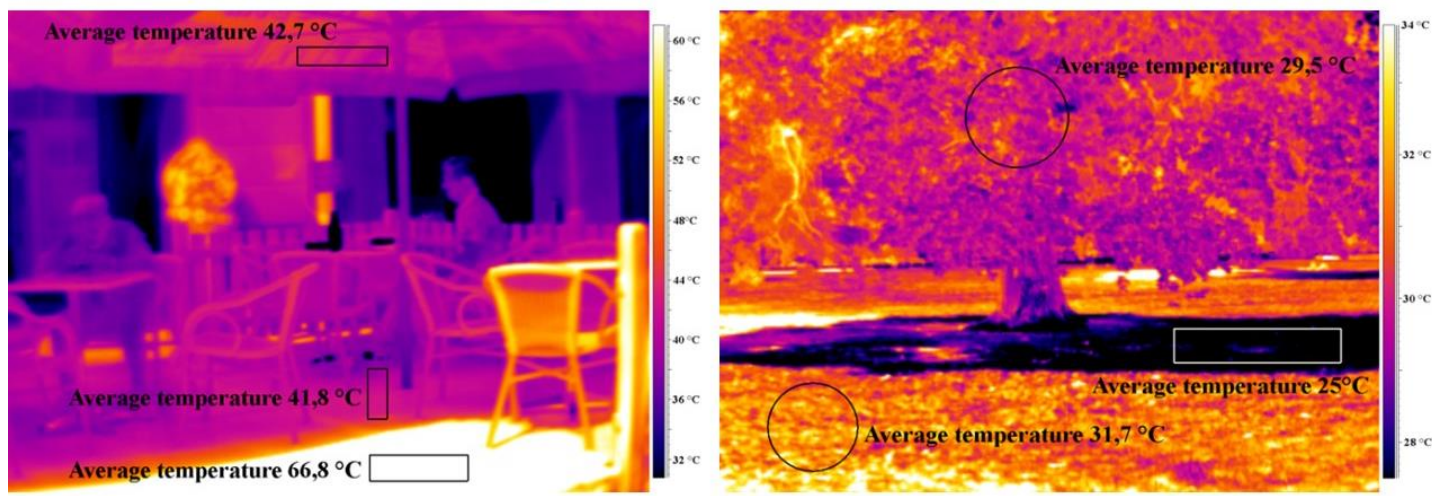

Fig.1: A thermovision picture used for the students' motivation at the beginning of the inquiry teaching activity. The average surface temperature in the shadow of the umbrella is $41.5 \circ \mathrm{o}$, while the average temperature in the shade under a tree is 25 oC so pupils are asked to think about a problem, particularly why the shadow under a tree is cooler than the shadow under an umbrella.

2. Exploration: During this phase, pupils make their own discoveries while the teacher provides scaffolding via observing, questioning and guiding (Carin, Bass, \& Contant, 2005). Pupils' groups are equipped with informative materials from the teacher relating to the principles of heat transfer via water vapor and condensation, solar radiation as well as water vapor from leaves. Based on this information, pupils should formulate their own hypothesis, which is to be corrected by the teacher into the final form: The tree cools its surrounding via heat energy consumption for water vapor through the leaves. Pupils are subsequently asked to verify this hypothesis by means of self proposed short outdoor experiment by using dry and wet towels exposed to the sun (Fig.2). Pupils 
measure surface temperatures by IR thermometers and realize that the temperature of the wet towel is cooler than the surface temperature of the dry one.

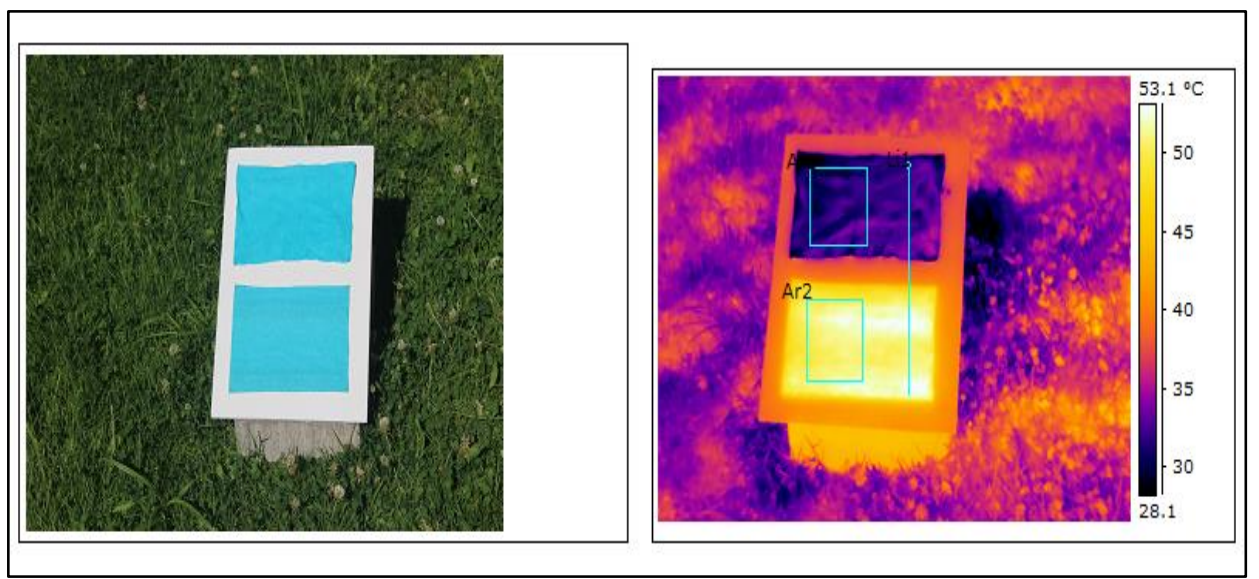

Fig.2: The pupils prove their hypothesis that the tree cools its environment by water vapor by means of a simple outdoor experiment, with dry and wet towels exposed to sun. The tree is simulated by the wet towel. The surface temperature measured by thermocamera or IR thermometer of the towel soaked with water is lower than the temperature of the dry towel.

3. Explanation. In this phase, the pupils in groups conclude their results and introduce their findings during the discussion with their peers and teacher. Finally, the teacher summarizes the findings through a short PowerPoint presentation and highlights the principles of cooling by means of water vapor from vegetation water retention in the landscape via short water cycle.

4. Elaboration. According to Carin, Bass, \& Contant (2005), during this phase, pupils should be capable of making connections between new principles and the real world. This is reached in our methodology via field measurements conducted in the nearby surroundings of the school or proximately in the school garden etc. (place-based education). Pupils measure solar radiation outside: the temperatures of different surfaces (the lawn, the pavement, the tree, the building etc.), comparing them and looking for the hottest (or coolest) surface etc. They provide and then discuss their findings in the real world together. In this manner they should realize how important plants, supplied with water, are for the cooling of our environment and what the effect of deforestation and urbanization has on local temperatures etc. At the end, they reach and present their conclusions and answer the initial question.

5. Evaluation. This phase provides the teacher with the possibility of assessing what the pupils have really learned. In this phase, the pupils are requested to draw into their worksheet a simple scheme of solar energy distribution in the landscape with vegetation. The assessment of this task enables the teacher to evaluate the level of the pupils' understanding. 


\subsection{Didactic survey on the impact of the activity on the improvement of pupils' knowledge}

An impact of the new teaching methodology on pupils' knowledge was tested via a pre-test/post-test survey. In a total 404 pupils from 14 Czech basic schools, $9^{\text {th }}$ grade, (14 - 15 years old) took part in this study. The pupils' prior knowledge was investigated in a pre-test using a questionnaire consisting of nine questions focussing on:

1) The cooling function of vegetation (example question: Explain why the air temperature is lower in the park with trees than on the paved town square during a hot summer day?) [open-type question]

2) Solar energy radiation and distribution (example questions: The amount of solar energy reaching in the lawn in front of your school during the sunny summer day is lower or higher than $600 \mathrm{~W} / \mathrm{m}^{2}$ ? From the total amount of solar energy reaching the earth's surface, plants use for photosynthesis more or less than $10 \%$ ?)

3) The understanding of heat energy conversion (example question: The morning dew condensing on a leaves a) warms up, or b) cools down the plant?)

4) Water regime of the plants (example question: Correctly complete the following sentence:

Plants absorb the water by the roots and...

a) use the whole amount of absorbed water for their metabolism and growth

b) use just a part of the absorbed water for their metabolism and growth, the rest of the water is stored in the vacuole

c) use just a part of the absorbed water for their metabolism and growth, the rest is vaporized into the air)

Each correct answer was assessed by 1 point; the maximum amount of was 9 points. The pupils underwent the post-test done via the same questionnaire immediately after the absolved teaching activity. The differences in a total score among pre-test and posttest were analysed using Students' t-test (The STATISTICA 12 PC package, StatSoft Inc.). At the end of the post-test the pupils were asked, if they have enjoined the education or not and why.

\section{Results of the didactic survey and discussion}

According to the results of the pre-test, we may conclude that the Czech pupils at their final grade of basic school taking part in our survey were not familiar with the cooling function of the vegetation in the landscape (Tab.1). They reached a very low total average amount of points during the pre-tests $(2,83 \pm 1.65$ Std. Dev. out of 9 possible points). They did not properly understand the causes of the differences in temperature between the park and town square. They explained the lower temperature in the park by the photosynthetic consumption of solar energy by trees and light absorption by the leaves ("there is a shadow under the tree"). Correct explanation (energy dissipation via transpiration) was mentioned just by $1 \%$ of respondents. The majority of the pupils believed that for the process of photosynthesis, more than $10 \%$ of incoming 
solar energy is used. The majority of the respondents $(64 \%)$ answered correctly, that during a summer day more than $600 \mathrm{~W} / \mathrm{m}^{2}$ reaches the lawn in front of the school. Hence, the students had quite correct preconception about the amount of solar energy reaching the earth's surface, but they did not know how this energy is distributed and utilized by vegetation. The amount of solar energy used for photosynthesis is overestimated, while the role of transpiration in solar energy dissipation is underestimated or even entirely unknown.

The poor understanding of water regime in plants followed also from the answers given to question related to transpiration. Merely $12 \%$ of the pupils answered properly that the plants vaporized water via the stomata into their environment. The majority believed that plants store all water in the vacuole and no water is released into the environment. This poor grasp of plant transpiration was discovered already by other scholars (Vitharana, 2015; Wang, 2004). Our survey performed among pre-service biology teachers also revealed a low understanding of plant transpiration and its impact on our environment (Ryplova \& Pokorny, 2019). Many pupils also answered the question concerning heat transfer by morning dew incorrectly. There was just one correct answer among all 404 respondents. Therefore we may credibly conclude that the pupils were not able to properly use the knowledge obtained in physics in a biological context. Despite the fact that heat energy, transformation via vaporization and condensation is taught at Czech schools in physics, this question was nevertheless still very difficult for the pupils.

Table 1: Summary of the pre-test/ post-test results, improvement of individual areas of pupils knowledge, $\mathrm{N}=404$.

\begin{tabular}{|l|l|l|l|l|l|}
\hline Focused area of knowledge & max. score & $\begin{array}{l}\text { mean score } \\
\text { pre-test }\end{array}$ & $\begin{array}{l}\text { mean } \\
\text { score } \\
\text { post-test }\end{array}$ & t & $\mathbf{p}$ \\
\hline $\begin{array}{l}\text { Understanding the cooling } \\
\text { function of vegetation }\end{array}$ & 3 & 1.07 & 2.36 & -8.03 & $\mathrm{p}<7.01^{*} 10^{-14}$ \\
\hline $\begin{array}{l}\text { Understanding the solar energy } \\
\text { distribution }\end{array}$ & 2 & 0.99 & 1.78 & -5.51 & $\mathrm{p}<7.9^{*} 10^{-7}$ \\
\hline $\begin{array}{l}\text { Understanding the heat energy } \\
\text { conversion (transdisciplinary } \\
\text { principles physics/biology) }\end{array}$ & 2 & 0.34 & 0.81 & -1.43 & $\mathrm{p}=0,11$ \\
\hline $\begin{array}{l}\text { Understanding water regime } \\
\text { of the plants }\end{array}$ & 2 & 0.42 & 1.31 & -12.02 & $\mathrm{p}<10^{-17}$ \\
\hline
\end{tabular}

The results of the post-test survey showed a measurably significant improvement of student understanding after the teaching (Fig. 3) in the total score as well as in particular questions. The respondents reached significantly higher total average amount of points (6. $26 \pm 2.24$ Std. Dev. out of 9 possible points, $\left.\mathrm{t}=-10.3, \mathrm{p} \leq 10^{-19}\right)$. More than $80 \%$ of the respondents answered properly in the post-test assessment that the main reason for the lower temperature in the park in comparison with the town square is water vapor from leaves. Additionally, their knowledge of plant water metabolism improved and they 
understood that the majority of solar energy is used for transpiration. Although significant improvement was detected in the case of the question concerning heat transfer by morning dew (41\% answered correctly), this score hint to weak ability of the respondents to use transdisciplinary relation between physics and biology. The majority of the pupils was fully engaged in the educational activities, especially regarding the outdoor temperature measurements. They have worked enthusiastically especially during the measurement with the thermocamera. More than $90 \%$ of the pupils enjoyed this type of education and $84 \%$ would like to undertake similar educational activities again. As to the reason why they preferred this educational method, the students indicated answers like: "Finally I understand how things around me work" or "It was amazing. We were not taught, actually, but we have learned so much!"

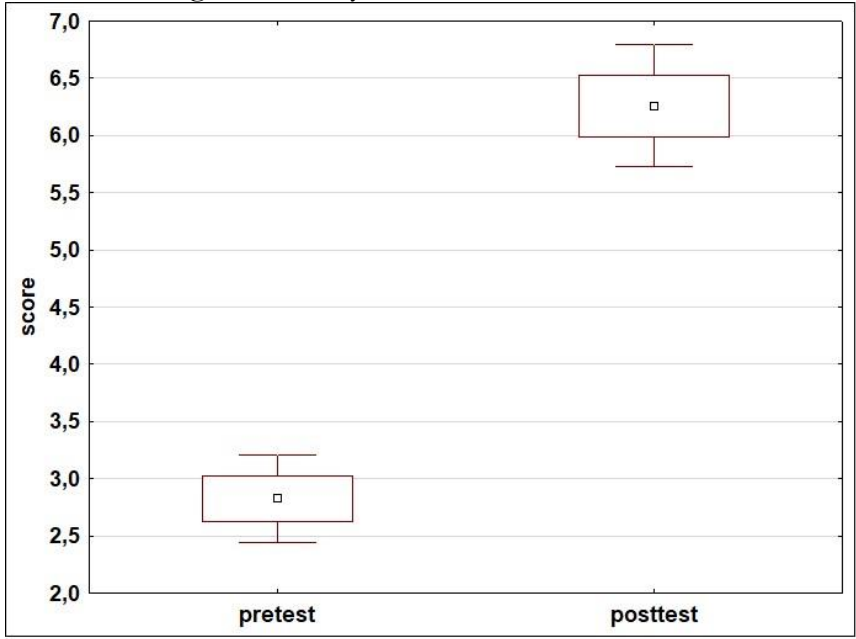

Fig.3: Mean test score reached by students in pre-test/post-test. Small squares represent mean values, boxes mean value $\pm 2{ }^{*}$ std. dev., line segments mean value $\pm 0.95{ }^{*}$ std. dev. $N=404$, (Students't-test $t=-10.3, p \leq 10^{-19}$ )

\section{Conclusions and implications:}

The role of vegetation for the water supply and solar energy distribution in the landscape is very important. However, according to the results of our didactic survey, that pupils' pre-instructional understanding of this function of vegetation is poor. The processes of solar energy distribution in the landscape are not known to Czech pupils of $9^{\text {th }}$ grade basic school, the photosynthesis is considered as the main energy consuming process while the role of transpiration in heat energy conversion is not understood. The transdisciplinary relations between physics and biology must be improved. Nevertheless, being blind to water recycling via vegetation could have big consequences for a sustainable environment.

The new teaching method developed for the education at basic schools improve significantly the pupils understanding of the role of vegetation in solar energy distribution and water cycle in the landscape and was received positively by the majority of the pupils. The developed methodology corresponds to modern trends of sustainable 
education like inquiry based education, place based education, multidisciplinary education, education supported by modern technology. The proposed instrumentation for measuring of solar radiation (in watts per $\mathrm{m}^{2}$ ) and surface temperature by IR thermometer is cheap, cost less than a simple notebook. The interpretation of data measured in field and their understanding requires just basic physics knowledge.

\section{Acknowledgement:}

This work was supported by the project TACR TL 01000294. The authors would like to thank T. Brcakova and M. Koudelkova for their help with data collection.

\section{References:}

Amprazis, A. \& Papadopoulou, P. (2020). Plant blindness: a faddish research interest or a substantive impediment to achieve sustainable development goals? Environmental Education Research, DOI: $10.1080 / 13504622.2020 .1768225$

Boyce, C. K. \& Lee, J. E. (2017). Plant Evolution and Climate over Geological Timescales. Annual Review of Earth and Planetary Sciences 45 (1), pp. 61-87.

Carin, A. A., Bass, J. E. \& Contant, T. L. (2005). Methods for teaching science as inquiry. 9th ed., Pearson Prentice Hall, Upper Saddle River, NJ.

Dai, A. \& Trenberth, K.E. (2002). Estimates of freshwater discharge from continents: latitudinal and seasonal variations. J. Hydrometeorol. 3, pp. 660-87.

Ellison, D., Morris, C. E., Locatelli, B., Sheil, D., Cohen, J., Murdiyarso, D., Gutierrez, V., van Noordwijk, M., Creed, I.F., Pokorny, J. (2017). Trees, forests and water: cool insights for a hot world. Global Environ. Change 43, pp.51-61.

Golding, C. (2009). Integrating the disciplines: Successful interdisciplinary subjects. Melbourn: Centre for the Study of Higher Education, University of Melbourne.

IPCC, (2018). Global warming of 1,5oC. Retrieved May 3, 2020 from http://www.ipcc.ch/report/sr15/

Kravcik, M., Pokorny, J. \& Kohutiar, J., (2008). Water for the recovery of the climate - A new water paradigm. Typopress Publishing House, Kosice.

Makarieva, A. M. \& Gorshkov V., G. (2007). Biotic pump of atmospheric moisture as driver of the hydrological cycle on land. Hydrol. Earth Syst. Sci. 11, pp. 1013-1033.

Makarieva A.M., Gorshkov V.G. \& Li B.L. (2009). Precipitation on land versus distance from the ocean: Evidence for a forest pump of atmospheric moisture, Ecological Complexity 6, pp. 302-307.

Orozco-Messana J., de la Poza-Plaza E. \& Calabuig-Moreno R. (2020). Experiences in Transdisciplinary Education for the Sustainable Development of the Built Environment, the ISAlab Workshop. Sustainability , 12, 1143; doi:10.3390/su12031143

Osborne, J., \& Dillon, J. (2008). Science Education in Europe: Critical Reflections. The Nuffield Foundation, London. Retrieved February 20, 2020, from http://hub.mspnet.org/index.cfm/ 15065

Pearce, F. (2020). Weather makers. Science 368 (6497), pp. 1302-1305.

Pokorny, J., Brom, J., Cermak, Hesslerova, P., J., Huryna, H., Nadezhdina, N., Rejskova, A. (2010). Solar energy dissipation and temperature control by water and plants, Int. J. Water, Vol 5, (4), pp. 311 336

Pokorny, J. (2019) Evapotranspiration. In: Fath, B.D. (editor in chief) Encyclopedia of Ecology, 2nd edition, vol. 2, pp. 292-303. Oxford: Elsevier.C 2019 Elsevier B.V.

Pokorny, J., Ryplova R. Hesslerova P., Jirka, V., Prochazka, M., Vacha , Z. (2020). Solar energy, Water in Landscape, Vegetation: a New Methodology for Education of Municipal Employees and Inovation of School Teaching on Management Effects on Regional Climate https://www.pf.jcu.cz/structure/departments/kbi/veda-a-vyzkum/nejvyznamnejsi-

projekty/tacr_slunecni_energie/ 
RIPL, W., 2003. Water: the bloodstream of the biosphere. Philosophical Transactions of the Royal Society of London B: Biological Sciences, 358 (1440), pp.1921-1934.

Rocard, M., Csermely, P., Jorde, D., Lenzen, D., Walberg-Herniksson, H., \& Hemmo, V. (2007). Science education NOW: A Renewed Pedagogy for the Future of Europe. Brussels, Belgium: Office for Official Publications of the European Communities. Retrieved May 18, 2020 from http://ec.europa.eu/research/science-society/document_library/pdf_06/report-rocardonscienceeducation_en.pdf.

Ryplova R. (2017). Inquiry education in botany - a way to cope with plant blindness? In M. Rusek, Vojir K. (Eds.), Project-based Education in Science Education: Empirical texts XV, (pp. 120 - 128). Prague: Charles University in Prague, Faculty of Education.

Ryplova R. \& Pokorny, J. (2018). Using project-based education to develop pre-service biology teachers' knowledge of the cooling effect of vegetation. In: M. Rusek, K. Vojir (Eds.), Project-based Education and other activating strategies in Science Education XVI., (pp.105 -113). Praha: Charles University, Faculty of Education.

Ryplova, R. \& Pokorny, J. (2019). Ignored Role of Vegetation in Solar Energy Distribution and Formation of Climate - Survey of the Knowledge of Novice Pre-service Science Teachers. Envigogika, 14(1). (in Czech)

Ryplova, R. \& Pokorny, J. (2020). Fostering interdisciplinarity through technology enhanced learning of transpiration. In M. Rusek, M. Tothova \& K. Vojir (Eds.), Project-based Education and Other Activating Strategies in Science Education XVII. (pp. 245-252). Prague: Charles University, Faculty of Education.

Sejak, J., Pokorny J., Seeley, K. (2018). Achieving Sustainable Valuations of Biotopes and Ecosystem Services Sustainability 10 (11), 4251.

Schneider, E.D. \& Sagan, D. (2005). Into the Cool, Energy Flow Thermodynamics and Life. The University of Chicago Press, Chicago \& London

Sheil, D. (2014) How plants water our planet: advances and imperatives. Trend Plant Sci 19. pp. 209-211

Sheil, D. (2018). Forests, atmospheric water and an uncertain future: the new biology of the global water cycle. Forest Ecosystem 5, 19. Retrieved May 3, 2019 from https://doi.org/10.1186/s40663-018$0138-\mathrm{y}$

Smith, G.A. (2007). "Place-Based Education: Breaking through the Constraining Regularities of Public School." Environmental Education Research 13(2). pp. 189-207.

UN, (2015). Transforming our world: the 2030 Agenda for Sustainable Development, New York.

Uno, G., E. (2009). Botanical literacy: How and what students should learn about plants. American Journal of Botany, 96, pp. $1753-1759$.

Vitharana, P.R.K.A. (2015). Student misconceptions about plant transport - a Sri Lankan Example. European Journal of Science and Mathematics Education 3 (3), pp. 275-288.

Wandersee, J. H. \& Schussler, E. E. (1999). Preventing Plant Blindness. The American Biology Teacher, 61(2), pp. 82-86.

Wang, J. (2004). Development and validation of a two-tier instrument to examine understanding of internal transport in plants and the human circulatory system International Journal of Science and Mathematics Education 2(2), pp. 131 - 157.

You, H.S. (2017). Why Teach Science with an Interdisciplinary Approach: History, Trends, and Conceptual Frameworks. Journal of Education and Learning 6(4), pp. 66-77. 